Sādhanā Vol. 38, Part 6, December 2013, pp. 1241-1257. (C) Indian Academy of Sciences

\title{
Numerical analysis of grid plate melting after a severe accident in a Fast-Breeder Reactor (FBR)
}

\author{
A JASMIN SUDHA* and K VELUSAMY \\ Nuclear and Safety Engineering Group, Indira Gandhi Centre for Atomic Research \\ (IGCAR), Kalpakkam 603 102, India \\ e-mail: jasmin@igcar.gov.in; kvelu@igcar.gov.in
}

MS received 2 January 2012; revised 11 August 2012; accepted 27 August 2012

\begin{abstract}
Fast breeder reactors (FBRs) are provided with redundant and diverse plant protection systems with a very low failure probability $\left(<10^{-6} /\right.$ reactor year $)$, making core disruptive accident (CDA), a beyond design basis event (BDBE). Nevertheless, safety analysis is carried out even for such events with a view to mitigate their consequences by providing engineered safeguards like the in-vessel core catcher. During a CDA, a significant fraction of the hot molten fuel moves downwards and gets relocated to the lower plate of grid plate. The ability of this plate to resist or delay relocation of core melt further has been investigated by developing appropriate mathematical models and translating them into a computer code HEATRAN-1. The core melt is a time dependent volumetric heat source because of the radioactive decay of the fission products which it contains. The code solves the nonlinear heat conduction equation including phase change. The analysis reveals that if the bottom of grid plate is considered to be adiabatic, melt-through of grid plate (i.e., melting of the entire thickness of the plate) occurs between $800 \mathrm{~s}$ and $1000 \mathrm{~s}$ depending upon the initial conditions. Knowledge of this time estimate is essential for defining the initial thermal load on the core catcher plate. If heat transfer from the bottom of grid plate to the underlying sodium is taken into account, then melt-through does not take place, but the temperature of grid plate is high enough to cause creep failure.
\end{abstract}

Keywords. Core disruptive accident; grid plate; melt-through; natural convection; enthalpy method.

\section{Introduction}

Fast breeder reactors are provided with redundant and diverse plant protection systems with a very low failure probability. Therefore, CDA is a beyond design basis event. But still it is analysed with a view to mitigate its consequences. An unprotected loss of flow accident (LOFA)

*For correspondence 
in a fast reactor can lead to core melt down depending on the severity of the accident. Molten core material relocation time following such an accident assumes importance from the safety perspective because decay heat $(\mathrm{P})$ contained in the core melt is a decreasing function of time (t) (i.e., $\mathrm{P} \propto \mathrm{t}^{-0.31}$ ). Longer the time taken to melt the grid plate, lesser will be the heat load on the core catcher plate. Core catcher is an engineered safety feature placed close to the bottom of the main vessel to contain and cool the core melt subsequent to grid plate failure. Therefore, a deterministic estimate of time needed for grid plate melting is essential for specification of initial thermal load on the core catcher plate (Roy Chowdhury 1998). Figure 1 is the vertical section of the reactor main vessel depicting the grid plate, core catcher and other essential internal structures.

In a core meltdown scenario, the molten fuel which is known as the core melt reaches the sodium inlet plenum and the lower plate of the grid plate is a solid obstacle for the molten corium to melt-through, before settling on the in-vessel core catcher. The core catcher is provided with proper slope and chimney arrangement for effective cooling of the core debris. This paper addresses the problem of 'grid plate melt-through' for some possible core melt configurations and boundary conditions.

Heat transfer studies related to molten material relocation have been carried out for reactors like BN 800, SPX-1 and CDFR to assess the time taken for the core debris to reach the core catcher (Dufour 2007; Niwa 1994; Voronov et al 1994). In these analyses, the time taken for melt-through of grid plate is assessed from a minimum of $100 \mathrm{~s}$ to $1200 \mathrm{~s}$ based on various assumptions and initial conditions. The present paper aims at finding the time required for grid

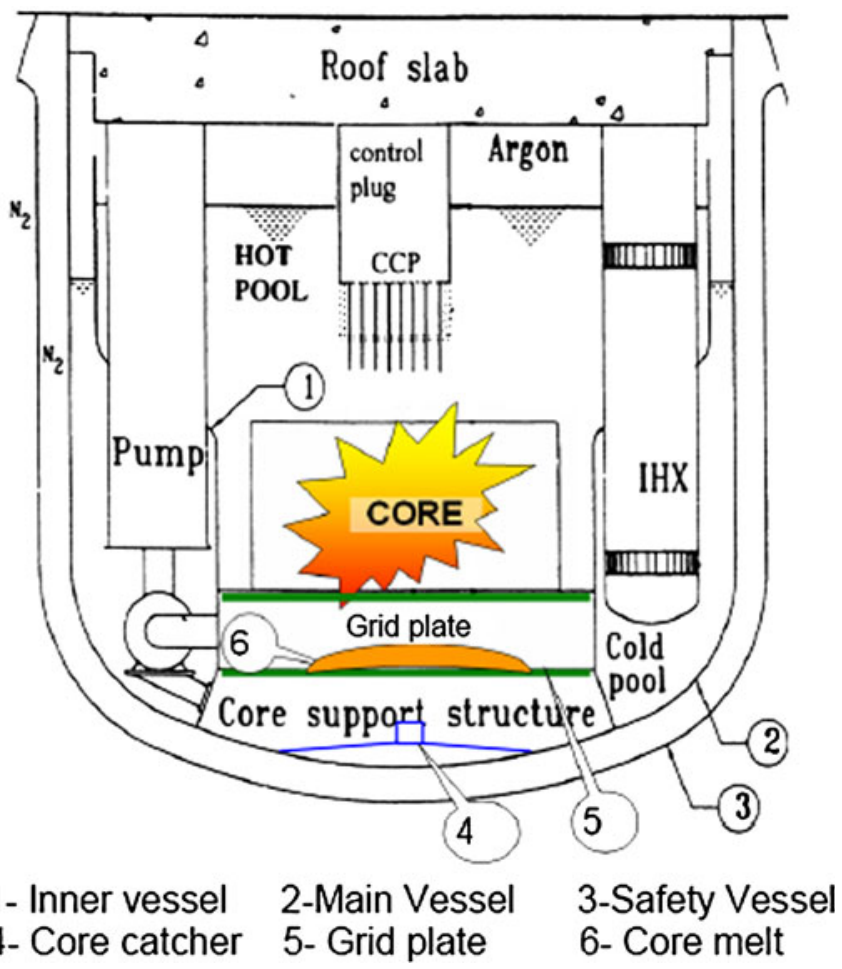

Figure 1. Vertical section of a FBR with degraded core after CDA. 
plate melt-through for the entire core settling on grid plate, assuming the radial extent of core melt on the plate to be a parameter which defines the thickness of the core melt. The time taken by the core melt to reach the plate is varied between 1 and $100 \mathrm{~s}$ and the corresponding decay heat.

\section{Problem definition}

The starting point of the present calculation is that the core melt rests on the lower plate of the grid plate, melting it as depicted in figure 2. One-dimensional computation is carried out in the axial direction $(\mathrm{z})$. The problem is treated as one-dimensional because of the fact that the grid plate is a plate of very large diameter of $6 \mathrm{~m}$ whereas its thickness is only $5 \mathrm{~cm}$. By the time the downward melting has propagated to the bottom of the plate, the radial extent of heat affected zone is also estimated to be approximately $5 \mathrm{~cm}$ only. Therefore, the $1 \mathrm{D}$ approximation is valid. The initial temperature of the grid plate is $673 \mathrm{~K}$, which is the cold pool temperature. Boundary condition at the bottom of grid plate is either adiabatic or convective. Decay heat generation within the fuel layer resting on the plate forms a time varying source term. The initial temperature of the fuel region is its melting temperature, $3020 \mathrm{~K}$.

Molten fuel is denser than the grid plate material, viz., stainless steel (SS). It is envisaged that as stainless steel melts, it will be displaced by the heavier fuel. It is a complex task to model the full system including flow and temperature change of fuel along with melting of grid plate. The focus of the present study is to assess the time for melting of the grid plate taking into account the displacement of molten steel which can accelerate the melting rate. The problem of molten material displacement is addressed numerically without going into the flow aspects but still preserving the essence of the problem.

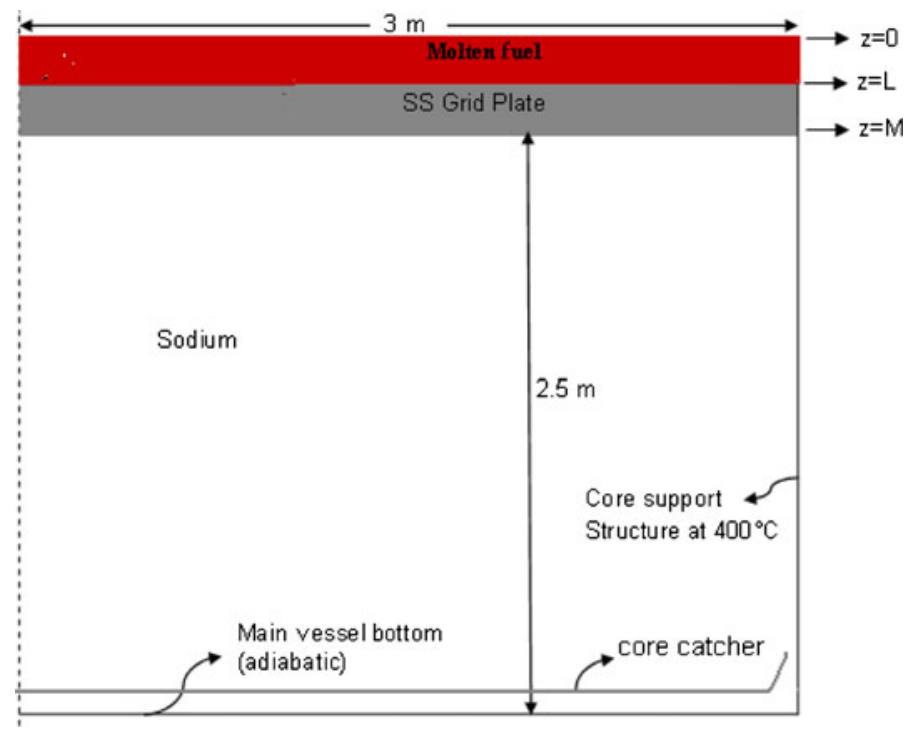

Figure 2. Schematic of the system. 


\section{Mathematical model}

The mathematical formulation of phase change problem is governed by partial differential equation of parabolic type. The location of the moving solid-liquid interface has to be obtained as a part of the solution (Venkateshan 2004; Ozisik 1977). An enthalpy method is adopted in the present study due to its advantage that the position of the interface can be found by comparing the enthalpy between the successive nodes (Ozisik 1994). The governing equations are as follows. Fuel region

$$
\rho_{f} \frac{\partial H_{f}}{\partial t}=\frac{\partial}{\partial z}\left(k_{f} \frac{\partial T_{f}}{\partial z}\right)+q^{\prime \prime \prime} .
$$

Initial and boundary conditions

$$
\begin{gathered}
T_{f}=\left(T_{o}\right)_{f}=3020 \mathrm{~K} . \\
H_{f}=\left(H_{o}\right)_{f}=C_{f}\left(\left(T_{o}\right)_{f}-\left(T_{m}\right)_{f}\right) \quad \text { at } \mathrm{t}=0 ; 0 \leq \mathrm{z} \leq \mathrm{L} .
\end{gathered}
$$

At $\mathrm{z}=0$, the fuel layer is adiabatic

At $\mathrm{z}=\mathrm{L}$,

$$
k_{f} \frac{\partial T_{f}}{\partial z}=k_{S S} \frac{\partial T_{S S}}{\partial z} .
$$

Grid plate region

$$
\rho_{S S} \frac{\partial H_{S S}}{\partial t}=\frac{\partial}{\partial z}\left(k_{S S} \frac{\partial T_{S S}}{\partial z}\right) .
$$

Initial and boundary conditions

$$
\begin{gathered}
T_{s s}=\left(T_{o}\right)_{s s}=673 \mathrm{~K} . \\
H_{s s}=\left(H_{o}\right)_{s s}=C_{s s}\left(\left(T_{o}\right)_{s s}-\left(T_{m}\right)_{s s}\right) \quad \text { at } t=0 ; \mathrm{L} \leq \mathrm{z} \leq \mathrm{M} .
\end{gathered}
$$

At $\mathrm{z}=\mathrm{M}$

$$
-k_{S S}\left(\frac{\partial T_{S S}}{\partial z}\right)=0 .
$$

(or)

$$
-k_{S S}\left(\frac{\partial T_{S s}}{\partial z}\right)=h\left(T-T_{N a}\right) .
$$

At melting point, enthalpy includes latent heat of fusion. Considering the melting temperature of fuel/stainless steel (depending on the region) as the reference temperature for calculation of enthalpy,

$$
\begin{array}{ccc}
H=C_{p}\left(T-T_{m}\right) & \text { for } & T \leq T_{m} . \\
H=C_{p}\left(T_{f}-T_{m}\right)+L & \text { for } & T>T_{m} .
\end{array}
$$

The definition of enthalpy as indicated above helps in minimizing the temperature oscillations usually encountered with the enthalpy method around the phase change temperature and it is termed relative enthalpy method. The inverse relationships to calculate temperature from enthalpy is given by

$$
\begin{aligned}
& T=T_{m}+\frac{H}{C_{p}} \quad \text { for } H<0 . \\
& T=T_{m} \quad \text { for } 0 \leq H \leq L . \\
& T=T_{m}+\frac{H-L}{C_{p}} \quad \text { for } H>L .
\end{aligned}
$$


Since an explicit scheme is used for time marching, the restriction imposed on the time step is that cell Fourier number, Fo $\leq 1 / 2$ for a stable solution. The governing equations are discretised using finite difference method in HEATRAN-1 code. Heat transfer coefficient between the grid plate bottom and liquid sodium ' $h$ ' is estimated through correlations obtained from a separate conjugate heat transfer study using computational fluid dynamics code PHOENICS.

\subsection{Voller's algorithm for tracking the interface}

In enthalpy method, the phase boundary or the melt front cannot be located precisely within a mesh at a particular time. If the moving melt front is to be located accurately and tracked, then interpolation has to be done. The algorithm proposed by Voller and Cross for accurate tracking of solid-liquid moving interface is incorporated in the code (Ozisik 1994).

A node ' $\mathrm{i}$ ' of width $\Delta \mathrm{z}$ with its neighbouring nodes $\mathrm{i}-1$ and $\mathrm{i}+1$ as illustrated in figure 3 , containing the solid liquid interface at the position $\mathrm{z}=\mathrm{s}(\mathrm{t})$ at any time $t$ is considered. $1 \mathrm{D}$ control volumes represented by ' $\mathrm{e}$ ' are drawn around each node. Let $\mathrm{f}$ be the fraction of this element which is solid and $(1-f)$ the fraction of the element which is liquid. The melt front is moving in the positive $\mathrm{z}$ direction. The total heat content of the element $\mathrm{e}_{\mathrm{i}}$ at any time $t$ can be approximated as $H_{\mathrm{i}} \Delta \mathrm{z}$ where $H_{\mathrm{i}}$ is the nodal enthalpy.

This total heat of the element may also be approximated as the sum of the heat in the solid and liquid parts of the element as

$$
C_{p} T_{l} f+\left(C_{p} T_{l}+L\right)(1-f) \Delta \mathrm{z}
$$

This implies that

$$
H_{l}=C_{p} T_{l} f+\left(C_{p} T_{l}+L\right)(1-f) .
$$

When the melt-front reaches the node $\mathrm{i}$ and is at the mid point, we have $f_{\mathrm{i}}=1 / 2$ and $T_{\mathrm{i}}=T_{m}$, then $H_{\mathrm{i}}$ can be rewritten as

$$
H_{l}=C_{p} T_{m}+\frac{L}{2}
$$

This result indicates that when the nodal enthalpy satisfies the above condition, the interface can be regarded as located on the node $i$.

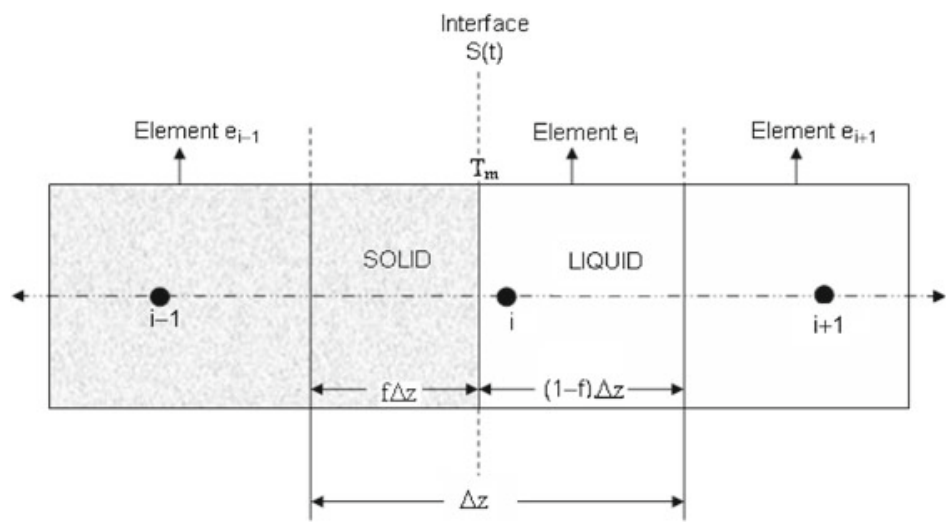

Figure 3. Interpretation of interface in enthalpy method. 
Based on the above interpretation of nodal enthalpy, Voller and Cross proposed the improved algorithm for tracking of the interface (Ozisik 1994). Whenever the enthalpy at the node point $i$ is such that

$$
H_{i}^{n}<\left(C_{p} T_{m}+\frac{L}{2}\right) \text { and } H_{i}^{n+1}>\left(C_{p} T_{m}+\frac{L}{2}\right) .
$$

The phase change boundary has crossed the node within that $\Delta t$. Assuming that the enthalpy changes linearly in any time interval, the time at which the the interface is on the node ' $\mathrm{i}$ ' is given by

$$
t_{\mathrm{i}}=(n+\beta) \Delta t,
$$

where the fractional time $\beta<1$ and is given by the linear interpolation

$$
\beta=\frac{\left(C_{p} T_{m}+\frac{L}{2}\right)-H_{\mathrm{i}}^{n}}{H_{\mathrm{i}}^{n+1}-H_{\mathrm{i}}^{n}} .
$$

Using this algorithm, $\mathrm{t}_{\mathrm{i}}$ the time at which the moving interface crosses the node $\mathrm{i}$ can be evaluated. For the relative enthalpy method the criterion for melt front crossing the node will be

$$
H_{\mathrm{i}}^{n}<\left(\frac{L}{2}\right) \quad \text { and } H_{\mathrm{i}}^{n+1}>\left(\frac{L}{2}\right),
$$

and the fractional time is also modified accordingly.

Figure 4a shows the typical staircase pattern of time history of location of the melt interface for a case study of $5 \mathrm{~cm}$ thick SS plate constantly exposed to core melt attack $(3020 \mathrm{~K})$ on its top side. Figure $4 \mathrm{~b}$ gives the interface locations after applying Voller's algorithm.

\subsection{Source term}

The core melt is a source of heat not only by virtue of its high initial temperature but also by the internal volumetric heat generation arising from the radioactive decay of the fission products which it contains. Reactor physics calculations for the fuel indicate that decay power is as high as $21 \%$ of reactor operating power $1 \mathrm{~s}$ after the accident. But it comes down rapidly to about $6 \%$ after one minute and $1.5 \%$ after an hour (Sridharan 2002). Taking into account of such time variations, the decay heat content (volumetric power density) is approximated by a function of the form

$$
q^{i \prime \prime}=86.5 \times 10^{6} /\left(t^{0.31}\right)
$$

as illustrated in figure 5. This forms the volumetric heat generation source term which rapidly decreases with time. It is assumed that core melt reaches the grid plate at times ranging from $1 \mathrm{~s}$ to $100 \mathrm{~s}$ after CDA which implicitly alters the initial heat load on the grid plate.

\subsection{Numerical modelling of molten material displacement}

Molten steel is lighter than the core melt. Therefore, molten steel gets displaced by the hot core melt as depicted in figure 6 which can accelerate the melting rate of the grid plate.

It is known that contact melting is a wide and complex area of study (Moallemi \& Viskanta 1985). Exact study of molten material displacement requires solution of flow and energy equations and also entails the use of free surface models combined with proper viscosity definition 


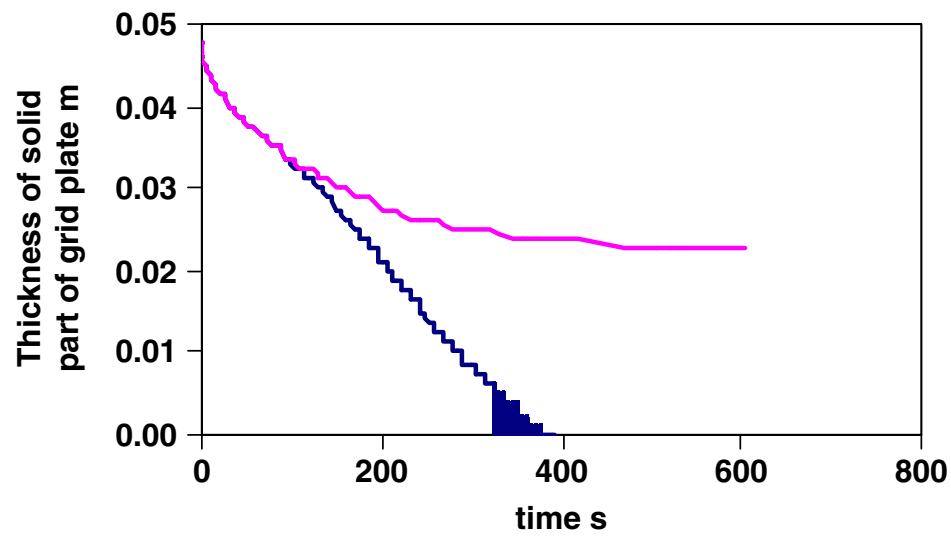

(a)
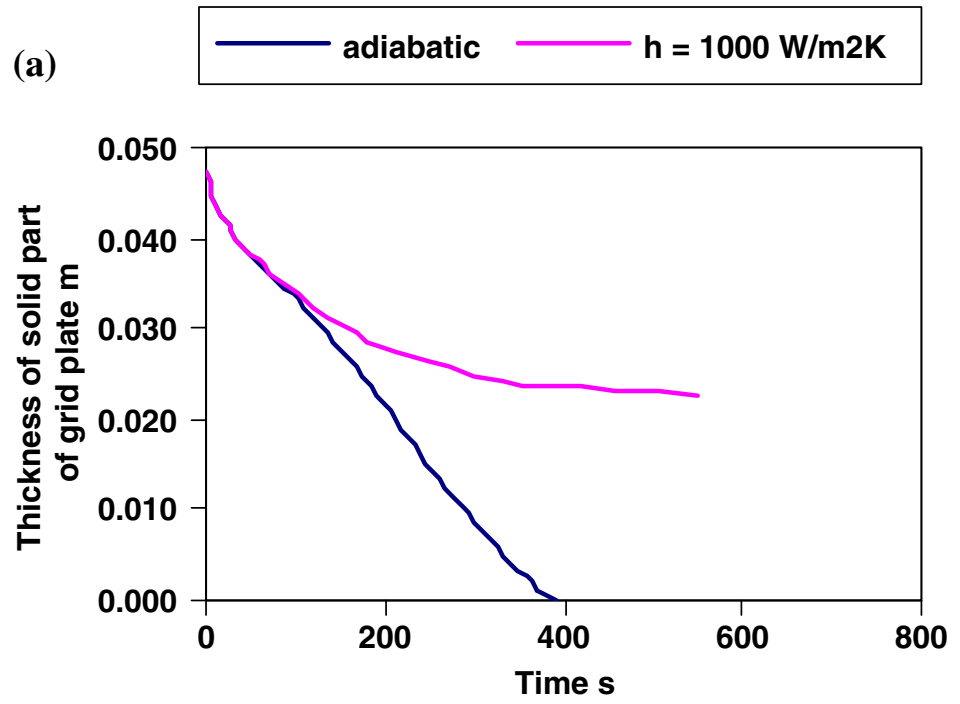

(b)

$$
\text { adiabatic } \mathrm{h}=1000 \mathrm{~W} / \mathrm{m} 2 \mathrm{~K}
$$

Figure 4. Interface tracking. (a) Normal enthalpy method and (b) with Voller's algorithm.

in Navier-Stokes equations. Moallemi in his study has obtained an expression for the film thickness of the melting object in contact with an isothermal heat source in terms of force due to apparent weight $F$ and Stefan number Ste as an expression given below (Moallemi \& Viskanta 1985; Chen et al 2008).

$$
\delta=\left(\frac{16 \times \text { Ste }}{5 F}\right)^{0.25} .
$$

In a similar study, Chen et al (2008) have pointed out that in this thin molten film, heat transfer is mainly by conduction. Hence, using a conduction code to such melting problems is justified. In the present study, the interface between the core melt and steel is not at constant temperature. Hence, the film thickness was calculated for the initial source temperature of $3020 \mathrm{~K}$ and also for the minimum interface temperature of $1720 \mathrm{~K}$. It is found that the film thickness varies from $1.55 \mathrm{~mm}$ to $0.55 \mathrm{~mm}$. Therefore, displacement is implemented in a simplified manner by 


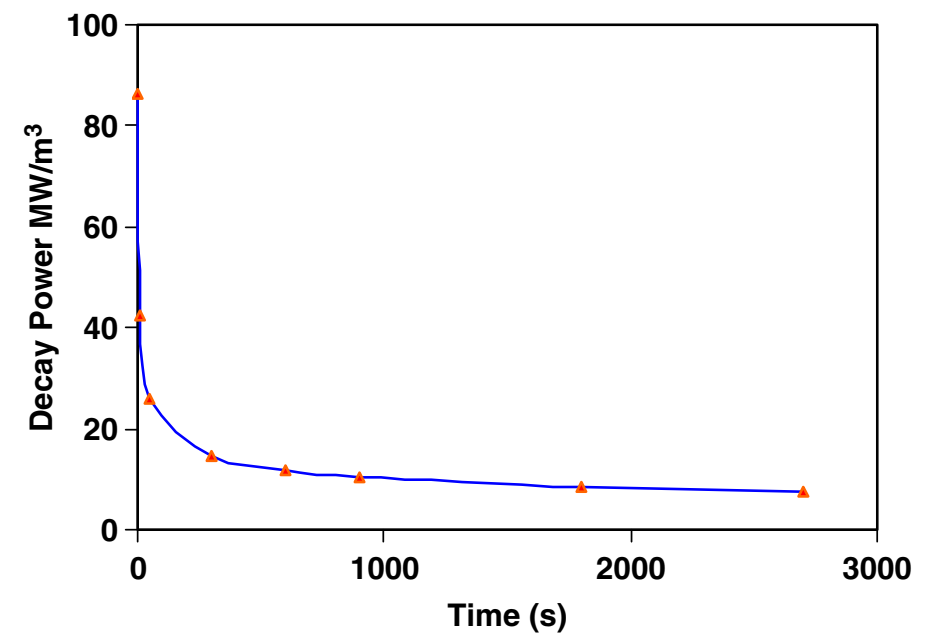

Figure 5. Decay heat as a function of time.

allowing the node of thickness $2 \mathrm{~mm}$ to melt completely and then removing it from the computational domain. Essentially, the thickness of the grid plate is redefined each time one of the nodes crosses the melting temperature. That is when the molten stainless steel film thickness exceeds $2 \mathrm{~mm}$, it is assumed to be displaced by the heavier core melt and then the film thickness is allowed to grow till $2 \mathrm{~mm}$ after which it is displaced. The same study is repeated by restricting the film thickness to $1 \mathrm{~mm}$ and the deviation in the melt-through time is found to be less than $1 \%$.

\subsection{Estimation of natural convection in sodium}

HEATRAN-1 requires heat transfer coefficient to be supplied as boundary condition at the bottom of the grid plate. For estimating natural convection in sodium plenum below the grid plate, the commercial CFD code PHOENICS has been employed since HEATRAN-1 is a conduction code. Correlations for Nusselt number are developed for transient and steady state conditions by carrying out conjugate heat transfer study. Heat transfer coefficients extracted from these correlations are used as boundary condition in HEATRAN-1 computations. The equations that govern natural convection of sodium are the continuity, $r$ and $z$ momentum equations, energy equation and equations for turbulent kinetic energy and its dissipation rate. Boussinesq approximation is incorporated to take care of the buoyancy effect in sodium and a low Reynolds number k-epsilon model was invoked to handle turbulence. No slip condition and impermeability of the wall are imposed as boundary conditions on the walls. The governing equations are listed below.
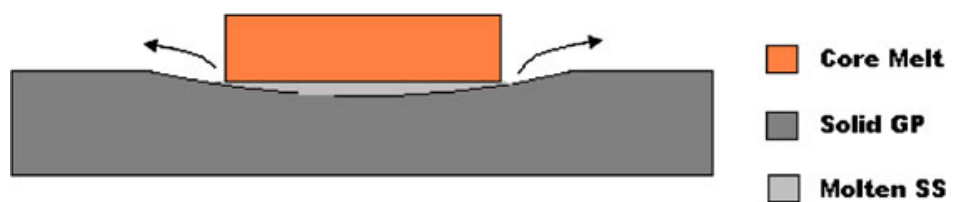

Figure 6. Molten stainless steel displaced by hot core melt. 
Continuity

$$
\frac{1}{r} \frac{\partial(r u)}{\partial r}+\frac{\partial v}{\partial z}=0
$$

Radial momentum

$$
\frac{\partial\left(\rho_{N a} u\right)}{\partial t}+\frac{\partial\left(\rho_{N a} u u\right)}{\partial r}+\frac{\partial\left(\rho_{N a} v u\right)}{\partial z}=-\frac{\partial p}{\partial r}+\frac{1}{r} \frac{\partial}{\partial r}\left(r \mu_{e f f} \frac{\partial u}{\partial r}\right)+\frac{\partial}{\partial z}\left(\mu_{e f f} \frac{\partial u}{\partial z}\right)-\mu_{e f f} \frac{u}{r^{2}} .
$$

Axial momentum

$$
\begin{aligned}
\frac{\partial\left(\rho_{N a} v\right)}{\partial t}+\frac{\partial\left(\rho_{N a} u v\right)}{\partial r}+\frac{\partial\left(\rho_{N a} v v\right)}{\partial z}= & -\frac{\partial p}{\partial z}+\frac{1}{r} \frac{\partial}{\partial r}\left(r \mu_{e f f} \frac{\partial v}{\partial r}\right) \\
& +\frac{\partial}{\partial z}\left(\mu_{e f f} \frac{\partial v}{\partial z}\right)+g \rho \beta\left(T-T_{r e f}\right) .
\end{aligned}
$$

Energy equation

$$
\begin{gathered}
\frac{\partial}{\partial t}\left(\rho_{N a} C_{N a} T_{N a}\right)+\frac{\partial}{\partial r}\left(\rho_{N a} C_{N a} u T_{N a}\right)+\frac{\partial}{\partial z}\left(\rho_{N a} C_{N a} v T_{N a}\right) \\
=\frac{1}{r} \frac{\partial}{\partial r}\left(r k_{e f f} \frac{\partial T_{N a}}{\partial r}\right)+\frac{\partial}{\partial z}\left(k_{e f f} \frac{\partial T_{N a}}{\partial z}\right) .
\end{gathered}
$$

Turbulent kinetic energy

$$
\begin{aligned}
\frac{\partial}{\partial t}\left(\rho_{N a} k\right)+\frac{\partial}{\partial r}\left(\rho_{N a} u k\right)+\frac{\partial}{\partial z}\left(\rho_{N a} v k\right)= & \frac{1}{r} \frac{\partial}{\partial r}\left[r\left(\mu+\frac{\mu_{t}}{\sigma_{k}}\right) \frac{\partial k}{\partial r}\right] \\
& +\frac{\partial}{\partial z}\left[\left(\mu+\frac{\mu_{t}}{\sigma_{k}}\right)\right] \frac{\partial k}{\partial z}+p_{k}+G_{k}
\end{aligned}
$$

Dissipation rate of turbulent kinetic energy

$$
\begin{aligned}
\frac{\partial}{\partial t}\left(\rho_{N a} \varepsilon\right)+\frac{\partial}{\partial r}\left(\rho_{N a} u \varepsilon\right)+\frac{\partial}{\partial z}\left(\rho_{N a} v \varepsilon\right)= & \frac{1}{r} \frac{\partial}{\partial r}\left[r\left(\mu+\frac{\mu_{t}}{\sigma_{\varepsilon}}\right) \frac{\partial \varepsilon}{\partial r}\right] \\
& +\frac{\partial}{\partial z}\left[\left(\mu+\frac{\mu_{t}}{\sigma_{\varepsilon}}\right)\right] \frac{\partial \varepsilon}{\partial z} \\
& +\left[c_{\varepsilon 1} f_{1}\left(P_{k}+C_{\varepsilon 3} G_{k}\right)-C_{\varepsilon 2} f_{2} \varepsilon\right] \frac{\varepsilon}{k}
\end{aligned}
$$

where

$$
\begin{aligned}
P_{k} & =\mu_{t}\left(2\left(\frac{\partial u}{\partial r}\right)^{2}+2\left(\frac{\partial v}{\partial z}\right)^{2}+2\left(\frac{v}{r}\right)^{2}+\left(\frac{\partial u}{\partial z}+\frac{\partial v}{\partial r}\right)^{2}\right) \\
G_{k} & =-\frac{\mu_{T}}{\sigma_{T}} g \beta \frac{\partial T}{\partial z} \\
v_{t} & =\frac{\mu_{t}}{\rho}=c_{\mu} f_{\mu} \frac{k^{2}}{\varepsilon}
\end{aligned}
$$




$$
\begin{aligned}
C_{\varepsilon 1} & =1.44, C_{\varepsilon 2}=1.92, C_{\mu}=0.09, \sigma_{k}=1.0, \sigma_{\varepsilon}=1.3 \\
f_{\mu} & =\left(1-e^{-0.0165 R_{y}}\right)^{2}\left(1+\frac{20.5}{\operatorname{Re}_{T}}\right) \\
f_{1} & =1+\left(\frac{0.05}{f_{\mu}}\right)^{3} \\
f_{2} & =1-e^{-\operatorname{Re}_{T}^{2}} \\
\operatorname{Re}_{T} & =\frac{k^{2}}{\varepsilon v} ; \quad R_{y}=\frac{k^{0.5} z}{v} .
\end{aligned}
$$

\subsection{CFD analysis}

Transient computations were carried out up to $1000 \mathrm{~s}$ in the lower plenum of the main vessel (figure 2) bounded on the top by the grid plate. Steady state was reached in about $400 \mathrm{~s}$. The aim of this exercise is to predict the transient natural convective heat transfer coefficient in sodium heated by grid plate which forms the top boundary and cooled by core support structure which forms the side wall of sodium plenum. The analysis revealed that heat transfer coefficient is initially high, i.e., $2500 \mathrm{~W} / \mathrm{m}^{2} \mathrm{~K}$ at about $10 \mathrm{~s}$ and it reduces to $785 \mathrm{~W} / \mathrm{m}^{2} \mathrm{~K}$ in the final steady state. The predicted velocity vectors at steady state are depicted in figure 7 .

The analysis also shows that the maximum steady temperatures reached at the interface between grid plate and sodium is $1125 \mathrm{~K}$, which is less than the saturation temperature of sodium at the prevailing pressure of $\sim 2$ bars. Therefore, it is established that downward film boiling of sodium is not anticipated below the grid plate. Hence, single phase heat transfer coefficient evaluated can be used as realistic boundary condition at grid plate bottom. Heat transfer coefficient in the transient regime as a function of time is given in figure 8.

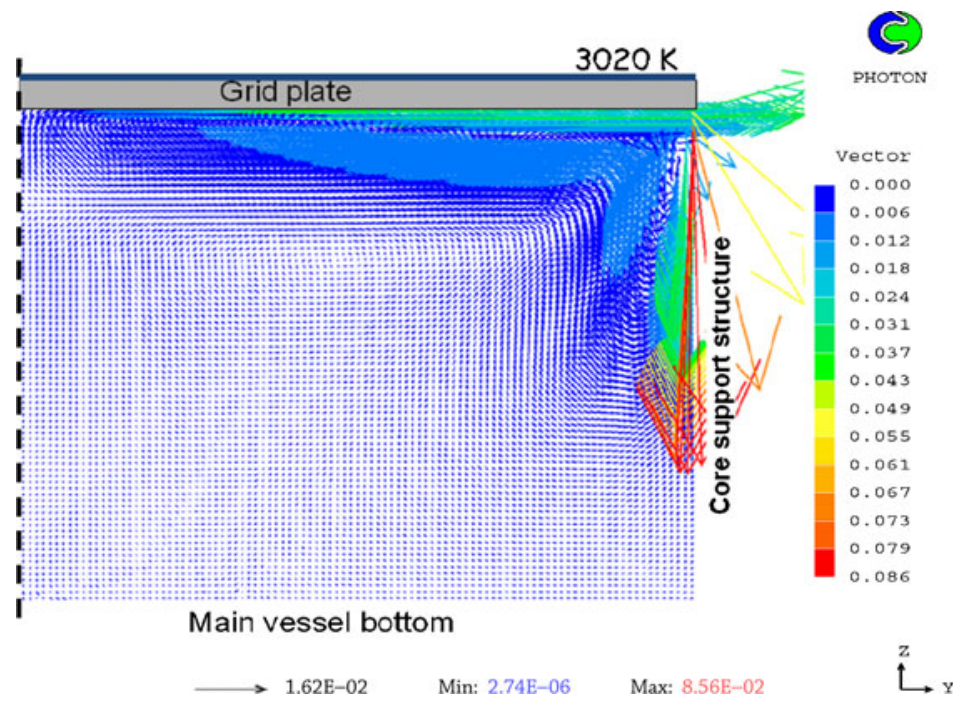

Figure 7. Sodium velocity in lower plenum. 


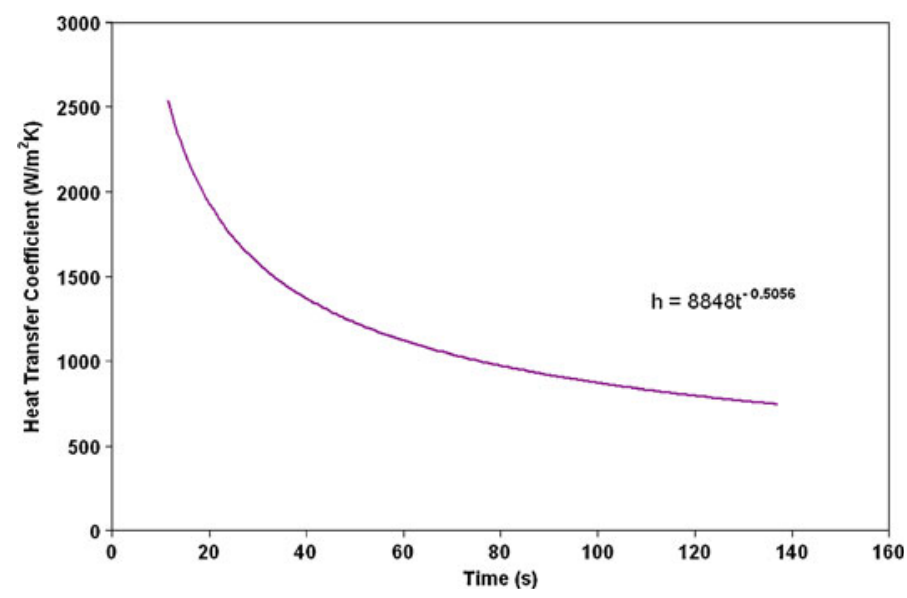

Figure 8. Transient heat transfer coefficient in liquid sodium below grid plate.

The transient heat transfer coefficient evaluated by the transient CFD simulation is correlated with time as

$$
h \propto \frac{k}{\sqrt{\alpha t}} \text { for } t \leq 120 \mathrm{~s},
$$

which, clearly indicates that conduction is the dominant heat transfer mechanism. Equivalently, it can be stated that in the unsteady state, Nusselt number is inversely proportional to square root of dimensionless time.

$$
N u_{\text {cond }}=\left(\frac{t}{\tau}\right)^{-0.5},
$$

where $\tau$ is the time constant of the system. Conduction dominated transient regime prevails up to $120 \mathrm{~s}$ for the computational domain of the present study. Then the change in temperature at grid plate bottom slows down and hence it can be assumed to exist in a quasi steady state at each temperature and heat transfer coefficient extracted from steady state correlation is adopted in the present study.

A parametric study has been performed by varying the constant temperature boundary on top of the plate and the steady state solutions are obtained for temperature and velocity fields. In the steady state, Nusselt number is correlated with Boussinesq number as

$$
N u_{\text {steady }}=0.45(B o)^{0.2} \text {. }
$$

Equations 28 and 29 are used to estimate the heat transfer coefficient at the grid plate bottom. The switch over from the Eq. (28) to Eq. (29) is effected in HEATRAN-1 computation when $h$ obtained from $N u_{\text {cond }}<N u_{\text {steady }}$, that is, when natural convective heat transfer induced by the presence of the side cooled wall takes over heat transfer by diffusion.

\section{Validation of computational models}

\subsection{Validation of HEATRAN-1 CODE}

4.1a Stefan problem: Considering the classical Stefan problem, the time taken for melt penetration up to a $5 \mathrm{~cm}$ thickness in a semi infinite slab of stainless steel with constant temperature 
boundary at one end is calculated from the analytical solution to be $194.4 \mathrm{~s}$. For validating HEATRAN-1 code with Stefan problem, a SS plate of thickness $50 \mathrm{~cm}$ was considered and the time to melt $5 \mathrm{~cm}$ thickness is estimated. Adiabatic bottom is assumed instead of an infinitely extending medium considered in theory and the case was solved using HEATRAN-1 code. Thickness of $50 \mathrm{~cm}$ was found to be sufficiently large compared to the $5 \mathrm{~cm}$ thickness which is to be melted and the effect of heating at the top surface was not felt at the adiabatic bottom, till the $5 \mathrm{~cm}$ thickness was molten. Melting temperature $(1700 \mathrm{~K})$ was imposed as the initial condition and the top boundary was held constant at $3020 \mathrm{~K}$. Constant properties were used. The time taken for melt penetration up to $5 \mathrm{~cm}$ thickness was estimated from the code to be $189.2 \mathrm{~s}$ and the discrepancy from the analytical solution is $2.7 \%$.

4.1b BN 800 benchmark data: Transient heat conduction and melt-through of lower portion of grid plate have been evaluated numerically for BN 800 reactor using a 1D code (Voronov et al 1994). Voronov has reported that under the most conservative assumptions of core melt lying above the grid plate at its boiling temperature and grid plate bottom assumed adiabatic and the time taken to melt the $11 \mathrm{~cm}$ thick grid plate is $1020 \mathrm{~s}$. Using HEATRAN-1, the same has been estimated as $1050 \mathrm{~s}$ and the discrepancy is only $3 \%$.

\subsection{Validation of PHOENICS model}

PHOENICS computations are validated by comparing the empirical Nusselt number obtained for natural convection in liquid sodium in a vertical cavity with that proposed by Mohamad \& Viskanta (1993). The vertical walls are differentially heated, while the horizontal walls are maintained adiabatic and Boussinesq number is $1.48 \times 10^{6}$. The numerically estimated Nusselt number 18.7 is compared with that of Mohamed and Viskanta and the error is less than 5\%.

\subsection{Grid sensitivity study}

4.3a PHOENICS code: In the present computation using low Reynolds number $\mathrm{k}-\varepsilon$ model, the number of nodes in the axial direction is optimized such that the typical value of $y+$ which is the nondimensional distance from the wall is close to one. Mathematically $y+$ is defined as $y^{+}=\frac{y u^{*}}{v}$, where $u^{*}$ is the wall shear velocity given by $\sqrt{\frac{\tau_{w}}{\rho}}$.

Hundred nodes along axial direction satisfy this criterion and in radial direction 50 nodes are found to be adequate. Increasing the number of nodes to 100 in radial direction altered the solution (grid plate bottom temperature) by only $0.7 \%$.

4.3b HEATRAN-1 code: For fuel thickness of $4 \mathrm{~cm}$ and grid plate thickness of $5 \mathrm{~cm}, 20$ nodes are taken in fuel and 25 nodes are taken in grid plate region, the grid size being $2 \mathrm{~mm}$. The study was repeated with grid size of $1 \mathrm{~mm}$ also. The difference between the grid plate temperatures predicted in these two mesh patterns is $<1 \%$ and hence, the grid size is fixed at $2 \mathrm{~mm}$.

\section{Results and discussion}

\subsection{Adiabatic grid plate}

In the first case study, grid plate bottom is taken to be adiabatic. The radial extent of core melt spreading on the grid plate is assumed to vary between $1 \mathrm{~m}$ and $3 \mathrm{~m}$, the former being the radius 
of the active core region and the latter being the radius of the grid plate itself. The thickness of the core melt varies accordingly, the mass of the core melt being constant in all the cases. Melt arrival time on the grid plate is the time taken by the core melt to get relocated to the grid plate from the core region after the accident. Deterministic calculations do not exist for this initial part of the accident and therefore this time estimate has been taken from information available in open literature and it is varied from $1 \mathrm{~s}$ to $100 \mathrm{~s}$ (Gluekler et al 1982). The predicted melt-through times are listed in table 1 for different conditions.

The results indicate that melt-through of grid plate can occur between $986 \mathrm{~s}$ and $1157 \mathrm{~s}$ for different times of arrival of core melt and different settling radii assuming that melting steel portion remains intact. A comparison is made between time estimates obtained with and without displacing the molten portion in grid plate and boiling portion in fuel. It is seen that for the plate thickness of $5 \mathrm{~cm}$, the observed change in melt-through time is only about $15 \%$ of total time needed. It is to be noted that the decreasing thickness of grid plate due to melting is partly compensated by the decreasing thickness of fuel region due to boiling on top at $3603 \mathrm{~K}$. Another reason is that when a melting node gets displaced and a relatively cooler node comes in contact with the interface, the interface temperature decreases marginally. This reduces the flux across the interface and hence the heating rate.

The predicted temperature history at a few important nodes is given in figure 9. The top of fuel initially at its melting point, remains at the same temperature for a while absorbing the latent heat and then its temperature increases steadily till it reaches the boiling point. The temperature of the bottom of the fuel initially decreases because of the heat exchange with cooler grid plate at $673 \mathrm{~K}$ and then rises up due to the continued volumetric heat generation. The grid plate bottom temperature increases and at melting point, absorbs its latent heat and then rises sharply because of increased diffusivity of liquid stainless steel. Melt-through is said to have occurred when the temperature at grid plate bottom just crosses the melting point.

The temperature profile across the fuel ( $2 \mathrm{~m}$ radius) and grid plate regions at various instants of time for adiabatic bottom of grid plate is shown in figure 10. It is observed that up to $300 \mathrm{~s}$ there is no phase change occurring in the grid plate and fuel regions. Then boiling of fuel top portion has resulted in reduced fuel thickness as seen in the time curve at $430 \mathrm{~s}$. Melting of grid plate region is complete at $950 \mathrm{~s}$. The melt interface is a moving one but it is shown stationary in figure 8 for ease of plotting. The reduction in the line lengths in the fuel and grid plate regions arise because of boiling/molten material displacement. The position of melt front for two different

Table 1. Grid plate melt-through time.

\begin{tabular}{lcccc}
\hline \multirow{2}{*}{$\begin{array}{l}\text { Radius of } \\
\text { fuel }(\mathrm{m})\end{array}$} & $\begin{array}{c}\text { Melt arrival } \\
\text { time }(\mathrm{s})\end{array}$ & $\begin{array}{c}\text { Normal (no material } \\
\text { displacement) }\end{array}$ & $\begin{array}{c}\text { Melting SS portion } \\
\text { only displaced }\end{array}$ & $\begin{array}{c}\text { Boiling fuel portion } \\
\text { also displaced }\end{array}$ \\
\hline 1 & 1 & 986 & 791 & 844 \\
& 10 & 1011 & 815 & 862 \\
2 & 100 & 1097 & 897 & 927 \\
& 1 & 990 & 799 & 861 \\
3 & 10 & 1014 & 823 & 879 \\
& 100 & 1101 & 909 & 873 \\
& 1 & 1037 & 850 & 893 \\
& 10 & 1063 & 874 & 968 \\
\hline
\end{tabular}




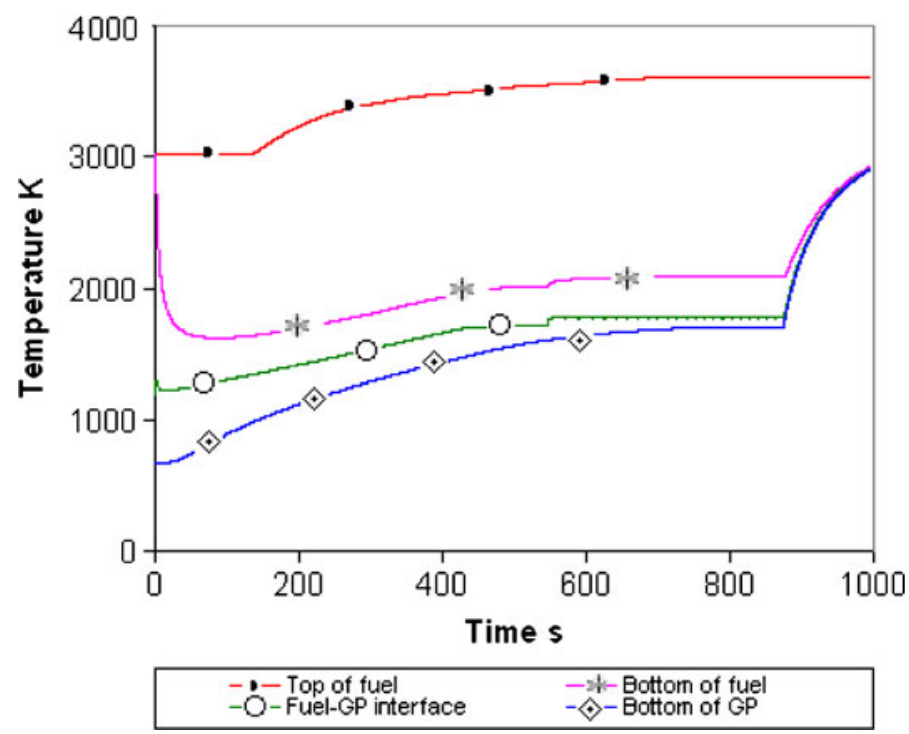

Figure 9. Temperature at selective nodes.

radial extents of molten fuel is presented in figure 11 . When the extent of spreading on grid plate is large, the fuel thickness comes down and it takes a longer time to melt-through the grid plate.

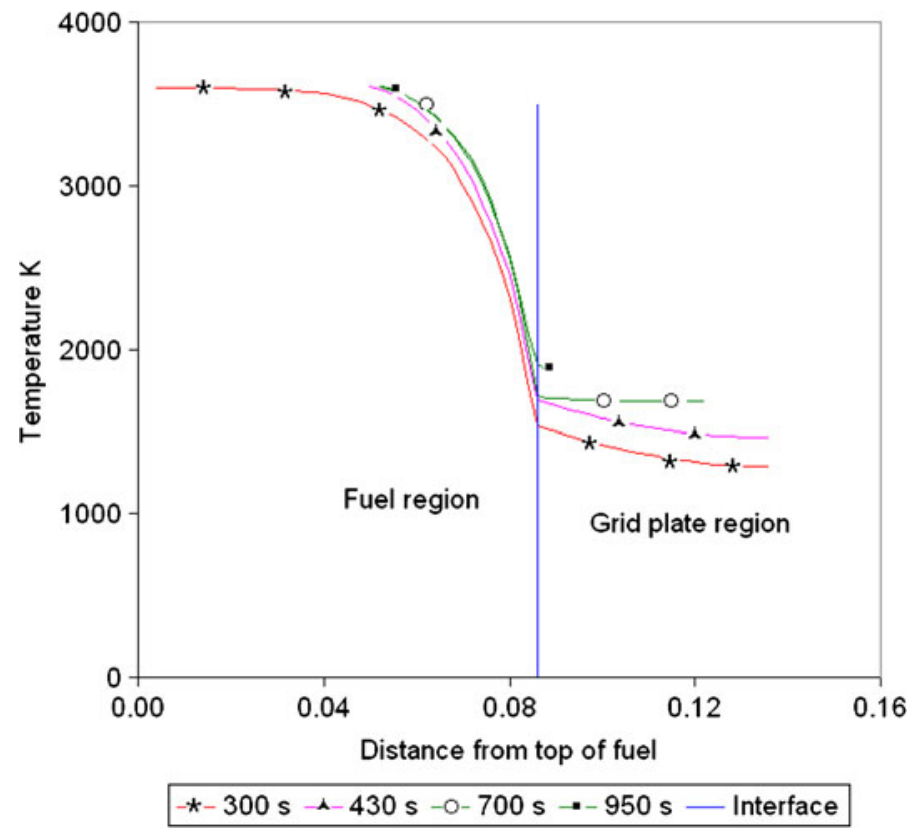

Figure 10. Temperature profile across fuel and grid plate. 


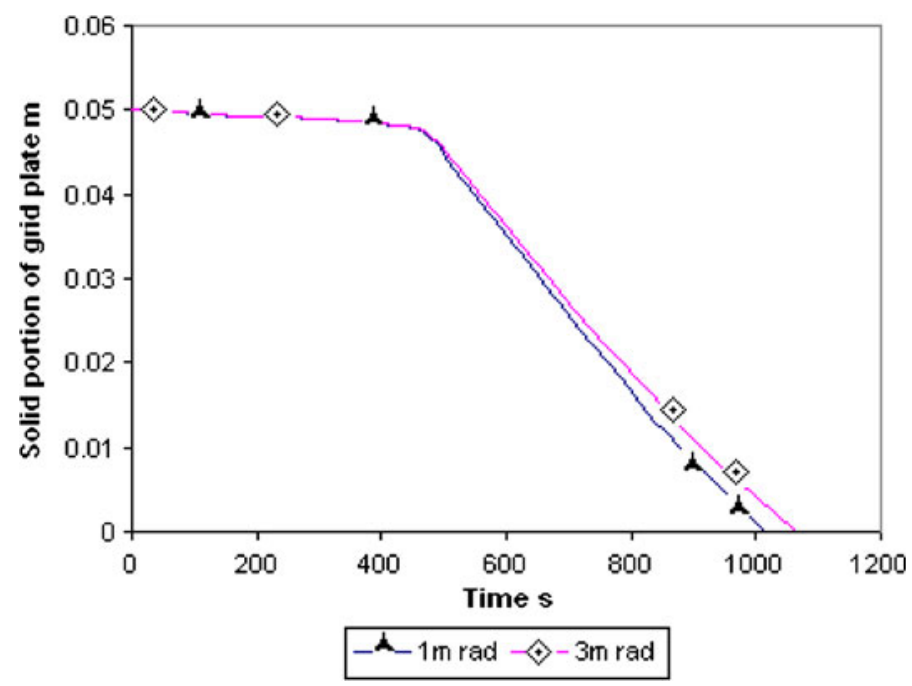

Figure 11. Melt front position.

\subsection{Grid plate exchanging heat with lower plenum}

In the next case, where heat exchange between grid plate and lower plenum is to be accounted, the transient natural convective heat transfer coefficient of sodium estimated using the PHOENICS code (figure 8 ) is prescribed as time varying boundary condition at grid plate bottom. Table 2 summarises the results of using constant and variable transient heat transfer (h) coefficients.

When heat transfer coefficient is prescribed at GP bottom, melt-through does not occur. The maximum temperature reached at grid plate bottom is $1120 \mathrm{~K}$, which is about $575 \mathrm{~K}$ lower than the melting point of GP. Also, it is clear from table 2 that the heat transfer coefficient calculated from general steady state correlations does not yield conservative results. It is prudent to use a transient heat transfer coefficient obtained from a conjugate heat transfer analysis as demonstrated here. Though the maximum temperature is less than the melting point of stainless steel

Table 2. Maximum temperature at grid plate bottom.

\begin{tabular}{|c|c|c|c|c|}
\hline \multirow{3}{*}{$\begin{array}{l}\text { Radius of } \\
\text { fuel (m) }\end{array}$} & \multirow{3}{*}{$\begin{array}{l}\text { Melt arrival } \\
\text { time (s) }\end{array}$} & \multicolumn{3}{|c|}{ Max. temperature at GP bottom $(\mathrm{K})$} \\
\hline & & \multirow{2}{*}{$\begin{array}{c}\text { Normal } \\
\mathrm{h}=1000 \mathrm{~W} / \mathrm{m}^{2} \mathrm{~K}\end{array}$} & \multicolumn{2}{|c|}{ Boiling fuel/Melting SS displaced } \\
\hline & & & $\mathrm{h}=1000 \mathrm{~W} / \mathrm{m}^{2} \mathrm{~K}$ & Transient $\mathrm{h}$ \\
\hline \multirow[t]{3}{*}{1} & 1 & 1074 & 1029 & 1119 \\
\hline & 10 & 1072 & 1026 & 1115 \\
\hline & 100 & 1061 & 1010 & 1097 \\
\hline \multirow[t]{3}{*}{2} & 1 & 1065 & 1028 & 1118 \\
\hline & 10 & 1062 & 1025 & 1115 \\
\hline & 100 & 1059 & 1010 & 1098 \\
\hline \multirow[t]{3}{*}{3} & 1 & 1040 & 1028 & 1117 \\
\hline & 10 & 1023 & 1025 & 1113 \\
\hline & 100 & 995 & 1003 & 1089 \\
\hline
\end{tabular}


and the boiling point of sodium, the temperature is high enough to cause failure of the plate by thermal creep at a later time.

\section{Conclusions}

The code HEATRAN-1 is used to analyse grid plate heating and melting sequence when decay heat generating nuclear fuel settles on it following a severe accident encompassing the whole core. Thermal analysis predicts grid plate melt-through time to be around $1000 \mathrm{~s}-1150 \mathrm{~s}$ after the core melt gets deposited on the grid plate, with no heat transfer to the underlying sodium. When molten material displacement is also modelled in the analysis, melt-through time decreases by about $15 \%-20 \%$ and it lies between $800 \mathrm{~s}-970 \mathrm{~s}$. This analysis gives a conservative estimate of time for grid plate melt-through.

When heat transfer to the lower sodium plenum is accounted for, by means of including heat transfer coefficient obtained from a CFD study using PHOENICS code as the boundary condition at the bottom side of the grid plate, HEATRAN-1 predicts that melt-through does not occur. The grid plate reaches a maximum temperature of $1120 \mathrm{~K}$, which is about $580 \mathrm{~K}$ less than the melting point of grid plate material. Nevertheless, grid plate failure can not be ruled out because the grid plate bottom temperature is in the creep regime.

Therefore this analysis shows that grid plate cannot serve as a permanent hold up place for the core melt expected from a whole core melt down accident. But it can substantially decrease the thermal load expected on the core catcher plate because the time delay involved in melting of grid plate decreases the decay heat content of core melt.

\section{Acknowledgements}

The authors wish to express their sincere thanks to Dr P Chellapandi, Director, Nuclear Safety Engineering Group and Mr BK Nashine, Head, Safety Engineering Division for their support. Thanks are also due to the reviewers for the meticulous review of the manuscript and useful suggestions.

\section{Nomenclature}

C Specific heat capacity

$\mathrm{H}$ Enthalpy

L Latent heat of fusion

$\mathrm{T}$ Temperature

Fo Fourier number

GP Grid Plate

h Heat transfer coefficient

$\mathrm{k}$ Thermal conductivity of plate/turbulent kinetic energy

L Thickness of the fuel

M Thickness of Grid Plate

$t$ Time

$u$ Radial velocity

$v$ Axial velocity

$\Delta \mathrm{T}$ Temperature difference

$\Delta \mathrm{z}$ Axial mesh size 


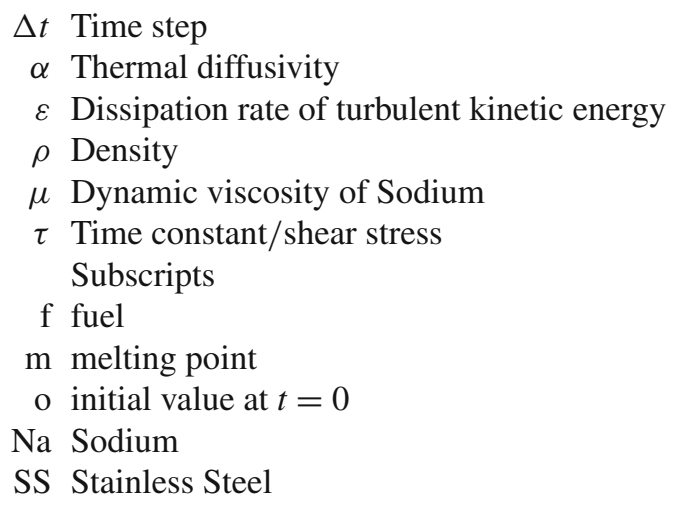

\section{References}

Chen W Z, Zhao Y S, Sun F R, Chen Z Y and Gong M 2008 Analysis of delta T driven contact melting of phase change material around a horizontal cylinder. Energy Conversion and Management 49(5): 1002-1007

Dufour 2007 Post accident heat removal analysis for SPX and EFR. CEA-IGCAR Tech. seminar on LMFR safety aspects related to severe accidents, IGCAR, Kalpakkam, India

Gluekler E, Hunsbedt A, Lam S T and Shahin A F 1982 Analysis of invessel core debris retention in large LMFBRs. Proc. of the LMFBR Safety Meeting, Lyon, 409-417

Moallemi M K and Viskanta R 1985 Melting around a migrating heat source. ASME J. Heat Transfer 107(2): 451-458

Mohamad A A and Viskanta R 1993 Modelling of turbulent buoyant flow and heat transfer in liquid metals. Int. J. Heat Mass Transfer 36(11): 2815-2826

Niwa H 1994 Future research needs on material interaction and re-location in LMFR safety, IWGFR-89, O-arai, Ibaraki, 579-593

Ozisik M N 1977 Basic heat transfer, NY: McGraw Hill, 128-148

Ozisik M N 1994 Finite Difference Methods in Heat Transfer, CRC Press, 275-305

Roy Chowdhury D G 1998 Sizing of Core catcher, Internal note: PFBR/31150/DN/1021/R-A

Sridharan 2002 Total Decay Heat Estimates in PFBR, PFBR/01115/DN/1118

Venkateshan S P 2004 First course in heat transfer, New Delhi: ANE Books, 458-465

Voronov S A, Kiryushin A I and Kuzavkov N G 1994 Evaluation of downmotion time interval of molten materials to corecatcher during CDA postulated in LMFR, Proc. of IWGFR89, O-arai, Ibaraki, 545-551 